\title{
Industry links with patient organisations
}

A healthy relationship is possible if based on integrity, independence, accountability, and transparency

\author{
Jeremy Taylor chief executive ${ }^{1}$, Simon Denegri NIHR national director for patients and the public \\ in research ${ }^{2}$
}

${ }^{1}$ National Voices, London, UK; ${ }^{2}$ University College London, London, UK

Are patient organisations overly influenced by industry funding? Two recent articles give fresh currency to a perennial debate. The first is a survey of a sample of leaders of patient advocacy organisations (439 surveyed, representing $5.6 \%$ of 7865 identified US patient advocacy organisations). The authors found that although most of the 289 organisations that responded reported modest industry funding, a minority had substantial support, raising concerns about their independence. Survey respondents acknowledged a need to improve conflict of interest policies. ${ }^{1}$ A second study of 104 patient advocacy organisations found similar funding patterns and that only $12 \mathrm{had}$ published policies for managing institutional conflicts of interest. ${ }^{2}$

Nobody disputes that funders of all types — regardless of whether they are from the public or private sector-can bias those in receipt of funding. There are well understood and researched risks for health professionals, researchers, and patient organisations alike. But to suggest on the basis of such surveys that patient groups are not sufficiently representing the interests of patients and citizens, as a linked opinion piece by Moynihan and Bero argues, ${ }^{3}$ is overdone. Nor is their proposal that patient groups should "ultimately disentangle" themselves from industry realistic in a health sector increasingly characterised by collaboration between public, private, and non-profit organisations.

Patient groups are diverse, but all are mission driven organisations trying to improve outcomes for particular groups of people. They can and should seek out appropriate relations with a range of partners, including industry. Funding is an important component of their activity, with the potential to do a great deal of good.

Patient organisations cannot be blamed for taking an interest in medicines. But many have a much wider role, ensuring that people get proper information and advice, a voice in their own care, practical and emotional support, and responsive and coordinated services. A cancer charity might take as much interest in housing, welfare, and employment as in cancer drugs. Viewing the non-profit sector in health and care only through the lens of medical treatment is a misunderstanding.
On the other hand, patient groups cannot plead that simply because they represent patients or have non-profit status that they are necessarily the good guys. Complacency serves only to fuel the criticisms levelled at them. The onus is undeniably on the organisations to demonstrate that they are well run in the interests of patients and the public.

Good leadership and strong governance are essential. Codes of conduct and guidance already exist for deciding when and how to work with industry and when not to. These highlight common values and principles, including clarity of purpose, integrity, independence, accountability, and transparency. They also provide examples of how such principles can be put into practice. $^{4-7}$

Patient organisations should seek a diversity of funding sources and consider each on its merits. All funding sources should be declared publicly along with the purpose for which money has been received. Conflicts of interest must be managed robustly and transparently, and all policies about funding and dealing with conflicts of interests made available to donors, supporters, and the public. Those who observe best practice have a stout defence of their conduct. Those that do not have few excuses.

Umbrella coalitions of patient organisations, such as England's National Voices, are well placed to encourage and support their members to follow published guidance and codes of conduct and to evaluate and review practice.

In addition, patient organisations should challenge themselves to ensure that patients have a strong role in how they are run and the decisions they take. For example, many patient organisations have adopted the James Lind Alliance priority setting partnerships methods to identify research priorities with patients, carers, and health professionals, independently of industry. ${ }^{8}$

This is both right in principle and an effective rejoinder to those who claim that patient organisations are in the pockets of corporate or governmental interests. What matters to patients and their families should be a golden thread through everything that the organisation does. 
Patient organisations should not be put off responsible working with industry for fear of guilt by association. Equally, each organisation must decide its own position on funding, and that will include-for some-refusing all funding from industry. Meanwhile, there are some signs that industry is seeking to work in a more open and constructive way with patient groups, although, by its own admission, it still has a great deal to learn. ${ }^{9}$ Successful collaborations will be able to demonstrate a clear purpose that benefits patients and ways of working that are based on the principles of integrity, independence, accountability, and transparency.

We thank the following members of The BMJs patient panel for helpful comments: Matthias Wienold, Dave deBronkart, Tamás Bereczky, Sally Crowe, Šarūnas Narbutas, and Angela Coulter.

Competing interests: We have read and understood BMJ policy on declaration of interests and declare the following interests: SD gives occasional paid advice to public bodies about patient engagement. National Voices receives funds from the pharmaceutical industry, including sponsorship for conferences and occasional paid advice on patient participation. Pharmaceutical funding has not exceeded $5 \%$ of total income in any of the last three years and is detailed in its publicly accessible annual reports and accounts.
Provenance and peer review: Commissioned; not externally peer reviewed.

1 Rose SL, Highland J, Karafa MT, Joffe S. Patient advocacy organizations, industry funding and conflicts of interest. JAMA Intern Med 2017;356:344-50. doi:10.1001/jamainternmed. and conflicts of interest. JAMA

2 McCoy MS, Carniol M, Chockley K, Urwin JW, Emanuel EJ, Schmidt H. Conflicts of interest for patient-advocacy organizations. N Engl J Med 2017;356:880-5. doi:10.1056/ NEJMsr1610625 pmid:28249131.

3 Moynihan R, Bero L. Towards a healthier patient voice: more independence, less industry funding. JAMA Intern Med 2017;356:350-1. doi:10.1001/jamainternmed.2016.9179 pmid: 28114596.

4 ABPI, National Voices. Working together, delivering for patients-a guide to collaboration between charities and pharmaceutical companies in the UK. 2015. http://www.abpi.org. uk/our-work/library/Documents/ABPI_NV_Guide_FINAL.pdf

5 Association of Medical Research Charities. An essential partnership: a guide for charities working with industry. 2014. http://www.amrc.org.uk/sites/default/files/doc_lib/Essential Partnership.pdf

6 European Patients' Academy. Guidance for patient involvement in industry-led medicines R\&D. https://www.eupati.eu/patient-involvement/guidance-for-patient-involvement-inindustry-led-medicines-rd/\#Overarching_principles_for_patient_involvement_throughout_ the_medicines_research_and_development_process

7 International Alliance of Patients' Organisations. Consensus framework. https://www.iapo. org.uk/consensus-framework-ethical-collaboration

8 James Lind Alliance Priority Setting Partnerships. Methods guidebook. http://www.jla.nihr. ac.uk/jla-guidebook/

9 ABPI. Patients and health and research experts unite to put patients first in medical research. Press release, 29 Nov 2016. http://www.abpi.org.uk/media-centre/newsreleases/ 2016/Pages/Patients-health-and-research-experts-unite-to-put-patients-first-in-medicalresearch.aspx

Published by the BMJ Publishing Group Limited. For permission to use (where not already granted under a licence) please go to http://group.bmj.com/group/rights-licensing/ permissions 